\title{
Research on the Shelf Display Strategy of Supermarkets in Amoy
}

\author{
Ziyun Yuan, Linbo Zhang*, Yanqi Wang, Yanyi Wu
}

International College, Xiamen University, Xiamen, China

*Corresponding author.Email: lbzhang@xmu.edu.cn

\begin{abstract}
In order to meet people's ever-changing shopping needs, the managers of supermarkets must improve their shelf display strategies. There are rarely any researches on the shelf display of supermarkets both from the perspective of the internal layout and commodity placement. Therefore, this study took the internal layout and commodity placement into consideration together to propose a more comprehensive improvement strategy. This paper took five most representative supermarkets in Amoy as the main research object to analyze the shelf display. The analysis and findings was based on magnet point theory and cue utilization theory, and finally put forward suggestions for shelf display optimization.
\end{abstract}

Keywords: Supermarket, Shelf display, Magnet point theory, Cue utilization theory.

\section{INTRODUCTION}

Since China joined the World Trade Organization in 2004, the domestic retail market has been fully opened to the world. As the industry with the greatest development potential in the retail industry, the number of supermarkets has exceeded 5,000 by the end of 2019 . However, due to the impact of e-commerce, many foreign supermarkets have withdrawn from the Chinese market, and the performance of physical supermarkets has also continued to decline. Some supermarkets have also experienced mergers and acquisitions, or even collapses.

In order to adapt to the ever-changing shopping needs, the managers of supermarkets need to further optimize the shelf display mode of supermarkets. Therefore, this paper mainly carried out field research on five representative supermarkets in Amoy, and combined with relevant theories for analysis. The aim is to put forward the optimal shelf display strategy for the managers of similar types of supermarkets to gain the maximum profit, and to bring better shopping experience to consumers as well.

\section{RESEARCH METHODS}

The research objects are RT-Mart (Xiamen store), Carrefour (Xiamen Zhong Hua Cheng store), Walmart (Xiamen World Mart store), Sam's Club (Xiamen Pilot Free Trade Zone store) and Metro (Xiamen Huli store).
Field research was carried out mainly on RT-Mart, Carrefour, Walmart, Sam's Club and Metro in Amoy to measure the height of shelves and the distance between shelves, and record the internal layout. Customers' action routes, shelf display, and customer gathering points in the five representative supermarkets were observed to provide sufficient information for analysis.

\section{RESULTS AND DISCUSSION}

\subsection{Analysis Based on Magnet Point Theory}

Based on magnet point theory and the distribution of the internal atlas of each supermarket, each supermarket is divided into five magnet points. Among them, black represents the first magnet point goods, such as vegetables, fruits, cooked food, milk, etc.; yellow represents the second magnet point goods, including some eye-catching web celebrity goods, popular goods; green represents the third magnet point goods that mainly the promotional goods located at the end of the display shelf; blue represents the fourth magnet point goods, including leisure food, clothing and other displayed with large quantities of goods; purple represents the fifth magnet point goods, generally used for large display, foil festive atmosphere of promotional goods; the gray indicates the location of the cash register, and the red indicates the entrances/exits and action routes. 


\subsubsection{RT-Mart}

There are three entrances and one exit in RT-Mart supermarket. Thought field investigation, it is found that entrances $\mathrm{B}$ and $\mathrm{C}$ with relatively large flow of people. Among them, the entrance $\mathrm{C}$ is the cooked food area with the largest purchase intensity and the largest number of buyers, which leads to serious congestion. The second magnet points are widely distributed to guide consumers to every corner of the supermarket. A large number of products of the fifth magnet point are displayed near the cashier desk, which seize the last purchase opportunity of customers when they leave the supermarket.

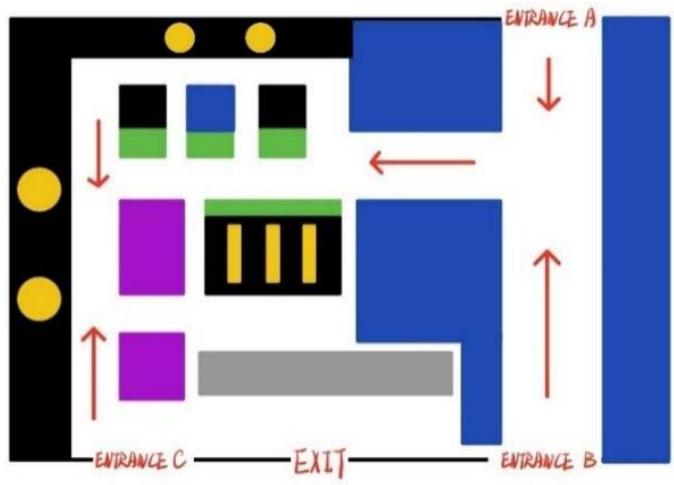

Figure 1 The plan of RT-Mart.

From the results, it can be seen that the serious crowding at the entrance $\mathrm{C}$ is the major problem of the RT-Mart internal space division. Since the food area is already the densest area in the supermarket, and new customers at the entrance are the root cause of the serious congestion in this area, the entrance $C$ should be closed to solve the problem. Meanwhile, the first magnet point goods, such as bread could be placed on both sides of the main path of entrance $\mathrm{A}$ and $\mathrm{B}$ for reducing the congestion in the food area.

\subsubsection{Carrefour}

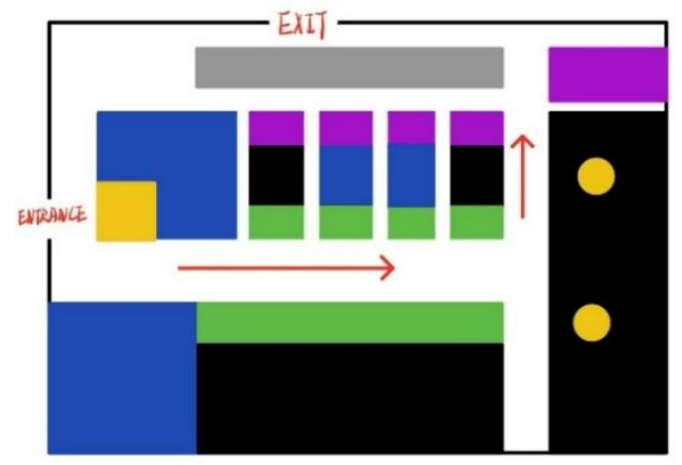

Figure 2 The plan of Carrefour.

Based on magnet point theory, the Carrefour is divided into five magnet points. Placing the commodities of the fourth magnet point in the main entrance with the largest flow of people does not maximize the sales profit.
Another disadvantage is that there are too few second magnet point goods, so it is difficult to attract customers to walk around the supermarket.

\subsubsection{Walmart}

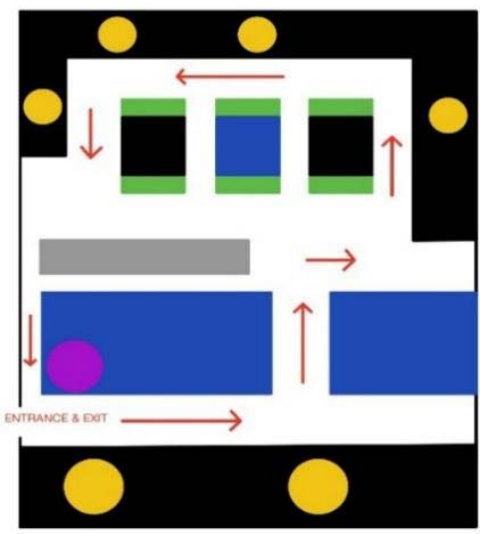

Figure 3 The plan of Walmart.

The Walmart is divided into five parts. The front area of the side of the main aisle is the second magnet point, which can make customers feel a strong festive atmosphere when they enter the supermarket. However, the fourth magnet point, the large amount of space at the back end of the main aisle is not utilized for displaying hot-selling goods. After going deep into the supermarket, the distribution of various commodity areas is relatively more in line with the requirements of the magnet point theory. There are only a few low-price promotional items near the cashier desk.

\subsubsection{Sam's Club}

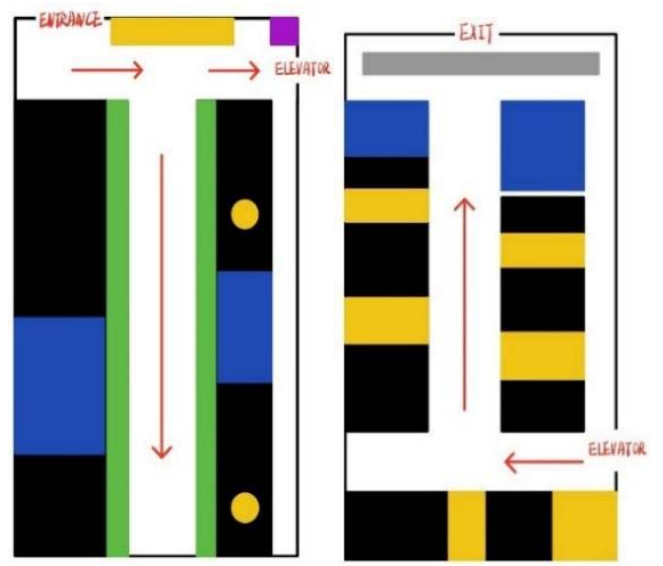

Figure 4 The plan of Sam's Club.

Sam's Club, as a stockroom-style supermarket, has two floors. Near the entrance, there is a large area of second magnet point goods on the left, which is very conducive to attract new customers. However, due to the overall lack of second magnet point goods on the second floor and the direct access to the first floor, the flow of people on the second floor was relatively small. In 
addition, the fifth magnet point near the elevator does not highlight the festive atmosphere. The second magnet point is located nearby the elevator on the first floor offering the most popular web celebrity commodity. While it is convenient for customers to select commodities, it also causes the crowding problem.

\subsubsection{Metro}

Usually, there is a large flow of people near the entrance. However, only a few kinds of goods are displayed in the fourth magnet point on the right side of the entrance. Deep inside the supermarket, it can be found that the first magnet goods in Metro are varied. Many imported goods here cannot be bought in other supermarkets. However, due to the irregularity of the goods placement and the lack of special lighting and decorative items, the degree of attraction and guidance of goods of the second magnet point to customers is reduced, and further result in the loss of sales profit. In the end, there are only a few common low-priced goods near the cashier desk without special area for placing some small convenience product, etc.

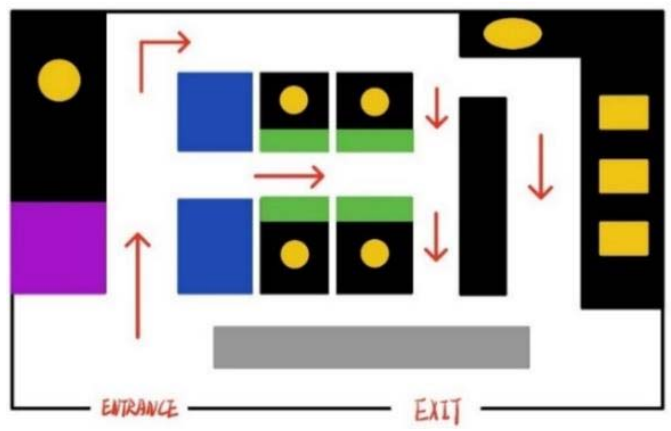

\subsection{Analysis Based on Cue Utilization Theory}

According to cue utilization theory, the display of commodities on shelves of supermarkets can leave a first impression on consumers. They are most likely to lower their evaluation of the commodity due to the bad display. Therefore, in order to achieve the purpose of increasing sales and customer satisfaction, supermarket managers should reasonably control the external cues of commodity placement on the shelf.

\subsubsection{The Height of Shelves}

Suitable shelf height is vital for consumers to take goods conveniently. On June 30, 2015, the State Council released that the national average height of adults aged 18 and above is $167.1 \mathrm{~cm}$ and $155.8 \mathrm{~cm}$ for male and female respectively. It can be inferred that the maximum height can be touched is about 1.8 meters. Over-height may cause inconvenience to consumers and thus reduce their purchase intention. The height that people can most easily see should be slightly lower than, or about equal to 1.8 meters, and the height that is most easily reached by hand is from the waist to the chest. Therefore, it is concluded that $1.5-1.7$ meters is the most easily visible height of the goods, and 0.85-1.2 meters is the most convenient height to take goods. The above two ranges are the best goods display height.

Figure 5 The plan of Metro.

Table 1. Shelf types of different supermarkets

\begin{tabular}{|c|l|}
\hline Brand & \multicolumn{1}{|c|}{ Shelf types } \\
\hline RT-Mart & Common shelves of 1.7 meters \\
\hline Carrefour & $\begin{array}{l}\text { Small shelves of 1.4 meters; } \\
\text { Promotional shelves of 0.7 meters; } \\
\text { Common shelves of 2.0 meters }\end{array}$ \\
\hline Walmart & $\begin{array}{l}\text { Small shelves of 1.4-1.5 meters; } \\
\text { Common shelves of 1.8-1.9 meters }\end{array}$ \\
\hline Sam's Club & Large shelves of 5 meters \\
\hline \multirow{2}{*}{ Metro } & $\begin{array}{l}\text { Large shelves of 5 meters; } \\
\text { Common shelves of 1.3-1.7 meters }\end{array}$ \\
\hline
\end{tabular}

(Source: sorted by this research)

Table 1 shows that most supermarket shelves have followed this rule, with a height of 1.4-1.8 meters. Sam's Club and Metro operates as a stockroom-style supermarket, with some shelves up to 5 meters high. However, the shelves above 1.8 meters in Sam's Club are all used for the stacking of inventory goods, and only the goods on sale are displayed on the shelves below 1.8 meters. However, in Metro, some goods are still displayed in the upper layers of shelves over 2 meters.

\subsubsection{Display of Goods}

RT-Mart: the same kind of goods are mostly displayed vertically, while the same series of goods are displayed horizontally. One shelf contains 3-4 kinds of goods. The display width of the same kind of goods is about 0.7-1.1 meters. The categories of goods are rich, but the replenishment is not timely, and there are often 
large vacancies of goods on the shelves. Goods in some areas are disordered.

Carrefour: a series of commodities are displayed vertically, but too many kinds of goods on the shelf. The shelf is narrow in width, and there are about 5-6 kinds of goods on one shelf.

Walmart: vertical display of similar goods and horizontal display of series goods. One shelf displays 23 kinds of goods, the width of which is between 0.8 meters and 1.2 meters. There are plenty of goods on the shelves with timely replenishment.

Sam's Club: horizontal display of series of goods, different kinds of goods are displayed every 1.2-2 meters, and 1-2 kinds of goods are displayed in each shelf. Most of the clothing are stacked instead of being hung. The display is messy with a sense of cheap.

Metro: the disordered goods in stock on the upper shelf tied with hemp ropes convey the cue of low quality. Untreated cartons can be seen everywhere in the aisles, which adds a sense of clutter to the whole supermarket. Commodity variety is efficient enough, but the display space is small. There are 7-8 kinds of goods on a shelf with display width ranging from 0.3-0.8 meters.

\subsubsection{Consumers' Perception of Adjacent Goods}

RT-Mart: In the fresh produce area, a chopping board with half a sheep hanging is placed in the middle of the aisle caused the horrible scene and feeling.

Carrefour: The aquatic area is connected with the vegetable and fruit area without physical partitions which causes the odor interference.

Walmart: Instant foods (such as bread) area and cooked area neighbored the seafood area. Seafood smell affects the appetite of the customer.

San's Club: The supermarket is neatly divided into more than a dozen rectangular areas, and the food area occupies one floor. The areas are clearly divided for avoiding odor interference. All meats, fruits and vegetables are well packaged. There are no slaughter areas.

Metro: The supermarket has no slaughter area, and the meat goods are packed and placed in the freezer, which increases the cleanliness of the supermarket. However, there is no physical partition between the areas that also bring the odors interference as Carrefour.

\section{CONCLUSION}

Overall, this research has real a variety of deficiencies of supermarkets' shelf display. For the shelf display improving in the future, the managers of supermarkets can pay attention to the internal layout and commodity placement.
Entering the entrance of the supermarkets, most of the fourth magnet point goods such as clothing, electrical appliances, and kitchen utensils are placed on both sides of the main aisle. As the aisle consumers must pass in the supermarket, both sides of it are the most important position for commodity sales. As the first magnet point in the whole store, the main commodity and the commodity with high purchase frequency should be placed here.

The non-fixed shelf in front of the cashier desk is the fifth magnet point, which should be used for large exhibitions, special sales activities or holiday promotions to attract customers' attention and enhance the atmosphere of the store.

There are too few second magnet points in some supermarkets. The few second magnet points make most customers only purchase goods in the main aisle. They are unwilling to go deep into the sub-channel area of each shelf, which leads to the problem that some goods are difficult to be found by customers. Such kind of problem should be solved by adding popular goods, or web celebrity goods.

1.5-1.7 meters is the most easily visible height of the goods, and 0.85-1.2 meters is the most convenient height to take goods. The above two ranges are the most reasonable goods display height. The height of top shelf should be controlled below 1.8 meters. The key goods on sale are placed in the middle of the shelf between 0.85 meters and 1.7 meters.

The goods display can be horizontal or vertical. For vertical display, heavier goods should be placed on the lower shelf and popular, low-priced and high-volume goods should be placed at the end of the shelf. Meanwhile, the goods with disgusting smell should be isolated from other goods.

\section{ACKNOWLEDGMENTS}

We gratefully acknowledge the financial support from Xiamen University for this research.

\section{REFERENCES}

[1] C.Y., Jiang Chongyang. Study on spatial layout and optimization of supermarkets in Changsha [D]. Changsha: Central South University of Forestry and Technology, 2015.

[2] I., Gilda, \& R., Kari. Architecture of an expert system for ergonomics analysis and design [J]. International Journal of Industrial Ergonomics, 1999.03: 205-221.

[3] J.S, Larson, \& E.T., Bradlow. An exploratory look at supermarket shopping paths [J]. International Journal of Research in Marketing, Vol. 22:395-414. 
[4] Q., Cai. Analysis of the influence of lighting on commercial space color [J]. China Collective Economy, 2021(08):58-59.

[5] L.W., Turley, \& R.E., Miliman. Atmospheric effects on shopping behavior: A review of the experimental evidence [J]. Journal of Business Research, 2000.09: 193-211.

[6] X.B Yuan. Analysis on the layout and display design of supermarkets [J]. Times Finance, 2010(06).

[7] X.Y., Lu. Research on Improvement of Operation Management of S Supermarket Based on Customer Satisfaction [D]. Guangzhou: South China University of Technology, 2014.

[8] Y.J., Liu. Analysis on the Space of stockroom-style supermarkets [D]. Chengdu: Southwest Jiaotong University, 2008.

[9] Z.L.,Cao. Study on Optimization of Internal Layout of D Boutique Supermarket [D]. Changchun: Jilin University, 2019.

[10] Z.J., Liu. Study on the layout of supermarkets in urban fringe from the perspective of supply and demand: A case study of Chang 'an District, Xi 'an [D]. Xi 'an: Northwest University, 2020. 